Check for updates

Cite this: Phys. Chem. Chem. Phys., 2021, 23, 329

Received 2nd October 2020, Accepted 4th December 2020 DOI: $10.1039 / \mathrm{d} 0 \mathrm{cp} 05195 \mathrm{k}$

rsc.li/pccp

\title{
Infrared action spectroscopy of nitrous oxide on cationic gold and cobalt clusters $\uparrow$
}

\author{
Ethan M. Cunningham, (D) a Alice E. Green, (D) a Gabriele Meizyte, (D) a \\ Alexander S. Gentleman, (DD ${ }^{a}$ Peter W. Beardsmore, ${ }^{a}$ Sascha Schaller, (D) ${ }^{b}$ \\ Kai M. Pollow, ${ }^{c}$ Karim Saroukh, ${ }^{c}$ Marko Förstel, (D) ${ }^{c}$ Otto Dopfer, (D) *c \\ Wieland Schöllkopf, (D) ${ }^{\mathrm{b}}$ André Fielicke (D) *bc and Stuart R. Mackenzie (D) *a
}

\begin{abstract}
Understanding the catalytic decomposition of nitrous oxide on finely divided transition metals is an important environmental issue. In this study, we present the results of a combined infrared action spectroscopy and quantum chemical investigation of molecular $\mathrm{N}_{2} \mathrm{O}$ binding to isolated $\mathrm{Au}_{n}{ }^{+}(n \leq 7)$ and $\mathrm{CO}_{n}{ }^{+}(n \leq 5)$ clusters. Infrared multiple-photon dissociation spectra have been recorded in the regions of both the $\mathrm{N}=\mathrm{O}\left(1000-1400 \mathrm{~cm}^{-1}\right)$ and $\mathrm{N}=\mathrm{N}\left(2100-2450 \mathrm{~cm}^{-1}\right)$ stretching modes of nitrous oxide. In the case of $\mathrm{Au}_{n}{ }^{+}$clusters only the ground electronic state plays a role, while the involvement of energetically low-lying excited states in binding to the $\mathrm{Co}_{n}{ }^{+}$clusters cannot be ruled out. There is a clear preference for $\mathrm{N}$-binding to clusters of both metals but some $\mathrm{O}$-bound isomers are observed in the case of smaller $\mathrm{CO}_{n}\left(\mathrm{~N}_{2} \mathrm{O}\right)^{+}$clusters.
\end{abstract}

\section{Introduction}

Nitrous oxide $\left(\mathrm{N}_{2} \mathrm{O}\right)$ is a potent greenhouse gas ${ }^{1,2}$ accounting for around $5 \%$ of anthropogenic emissions and has a warming potential almost 300 times greater than carbon dioxide. ${ }^{3}$ As a result, there is considerable interest in reducing $\mathrm{N}_{2} \mathrm{O}$ emissions, especially from automobile combustion engines. To this end, modern vehicles employ metal-catalysed nitrogen oxide reduction in their three-way catalytic converters. ${ }^{4,5}$ The transition metals used are usually found in a highly dispersed form such as nanoparticles and the study of small isolated metal clusters is thus a vibrant and active research area. ${ }^{6}$ Understanding the physical and chemical properties of transition metal clusters has wider importance in the fields of heterogeneous catalysis, solid-state physics, surface chemistry, and organometallic chemistry. ${ }^{7-11}$ In this context, gas-phase metal clusters represent tractable model systems for developing molecular level insight into the thermodynamics and kinetics of catalytic reactions. Decades of work have shown that this activity depends on a complex interplay of various factors,

\footnotetext{
${ }^{a}$ Department of Chemistry, University of Oxford, Physical and Theoretical Chemistry Laboratory, South Parks Road, Oxford OX1 3QZ, UK. E-mail: stuart.mackenzie@chem.ox.ac.uk

${ }^{b}$ Fritz-Haber-Institut der Max-Planck-Gesellschaft, Faradayweg 4-6, 14195 Berlin, Germany.E-mail: fielicke@fhi-berlin.mpg.de

${ }^{c}$ Institut für Optik und Atomare Physik, Technische Universität Berlin, Hardenbergstr. 36, 10623 Berlin, Germany. E-mail: dopfer@physik.tu-berlin.de $\dagger$ Electronic supplementary information (ESI) available. See DOI: 10.1039/ d0cp05195k
}

including size, geometry, local charge density, dimensionality, electronic structure, and the presence as well as properties of defect sites. ${ }^{12-21}$

Many experimental studies have investigated the structural evolution of isolated gold clusters with atom number. ${ }^{22-24}$ Early investigations utilised ion mobility mass spectrometry, which, combined with quantum chemical calculations, is a powerful tool for structure determination of charged metal clusters. ${ }^{25}$ Kappes and coworkers have performed such studies on charged gold clusters up to $n=14^{26,27}$ and determined planar groundstate structures for $\mathrm{Au}_{n}{ }^{+}(n=3-7)$ and $\mathrm{Au}_{n}{ }^{-}(n=3-11)$, respectively. Anionic gold clusters were investigated further by electron diffraction confirming these structural motifs, revealing a possible chiral structure for $\mathrm{Au}_{34}{ }^{-28,29}$ Building on previous spectroscopic studies of $\mathrm{Au}_{n}^{+}(n \leq 5)$ clusters, ${ }^{30-33}$ Ferrari et al. have recently reported far-infrared multiple photon dissociation spectroscopy (IR-MPD) studies of $\mathrm{Au}_{n}^{+}$ $(n \leq 9)$, identifying both 3D and planar isomers for $n=8 .^{34}$ IR-MPD studies have also been performed on neutral gold clusters up to 20 gold atoms, revealing two-dimensional, planar structures up to $\mathrm{Au}_{10}$, with the onset of 3D structures for $\mathrm{Au}_{11}$ at $100 \mathrm{~K} \cdot{ }^{35-37}$ At room temperature, however, planar and non-planar isomers coexist for $\mathrm{Au}_{8}, \mathrm{Au}_{9}$, and $\mathrm{Au}_{10}$. The largest cluster studied, $\mathrm{Au}_{20}$, was shown to have a pyramidal structure. ${ }^{38}$

Reactions between cationic gold clusters, $\mathrm{Au}_{n}{ }^{+}(n=1-4)$, and $\mathrm{N}_{2} \mathrm{O}$ have been studied by Dietrich $e t$ al. combining a Penning trap with time-of-flight (ToF) mass spectrometry. ${ }^{39}$ Dissociative charge transfer yielding $\mathrm{Au}_{n} \mathrm{~N}$ and $\mathrm{NO}^{+}$was the major reaction channel for $n=1$ and 2, but a range of other products, including 
$\mathrm{Au}_{n} \mathrm{O}^{+}, \mathrm{Au}_{n} \mathrm{~N}^{+}$and $\mathrm{Au}_{n} \mathrm{NO}^{+}$, were also detected, with $n=1$ and 3 clusters leading preferentially to $\mathrm{N}=\mathrm{O}$ bond rupture and the $n=2$ cluster breaking the $\mathrm{N}=\mathrm{N}$ bond. Relevant structural information on nitrogen oxides adsorbed to gold clusters is limited to the IR-MPD study of $\mathrm{Au}_{n}(\mathrm{NO})^{+}$by Fielicke and coworkers. ${ }^{40}$ Marked nitric oxide activation was observed in binding to the odd-electron, even- $n, \mathrm{Au}_{n}{ }^{+}$clusters, reflecting efficient unpaired electron donation into the NO $\pi^{*}$ orbital. NO was found to bind non-linearly in atop arrangements, tending to favour low-coordinated gold atoms.

Gehrke et al. have employed IR-MPD to identify the structures of $\mathrm{Co}_{n}{ }^{+}-\mathrm{Ar}(n=4-8)$ clusters. ${ }^{41}$ All clusters observed exhibit high spin states and significant Jahn-Teller distortion and, unusually, the vibrational spectra of $\mathrm{Co}_{n}{ }^{+}$were shown to be strongly dependent on the number of adsorbed $\mathrm{Ar}$ messenger atoms. More recently, an IR-MPD study by Jia et al. on $\mathrm{Co}_{n}{ }^{+}-\mathrm{Ar}_{m}(n=3-5, m=3,4)$ confirmed these structural findings, ${ }^{42}$ and the high spin states of isolated $\mathrm{Co}_{n}{ }^{+}(n=4-9)$ clusters have been measured by X-ray absorption and X-ray magnetic circular dichroism spectroscopy. ${ }^{43}$ The structures of neutral $\mathrm{Co}_{n}$ clusters $(n=4-10,13)$ have also been studied using two-colour IR-UV spectroscopy. ${ }^{44}$

Reactions of $\mathrm{Co}_{n}{ }^{+}(n=4-30)$ clusters with NO and $\mathrm{N}_{2} \mathrm{O}$ have been investigated using Fourier transform ion cyclotron resonance (FT-ICR) mass spectrometry under single-collision conditions. ${ }^{45}$ Reactions with $\mathrm{N}_{2} \mathrm{O}$ typically proceed much more slowly than the collision rate and result in the formation of simple cluster oxides, $\mathrm{Co}_{n} \mathrm{O}_{m}{ }^{+}$. By contrast, NO chemisorption rates exceed calculated collision rates. In both reactions there is evidence for cluster fragmentation, characterised typically by Co atom evaporation, and multiple collisions result in $\mathrm{N}_{2} \mathrm{O}$ decomposition leading to $\mathrm{N}_{2}$ loss. No molecularly adsorbed, i.e. $\mathrm{Co}_{n}\left(\mathrm{~N}_{2} \mathrm{O}\right)^{+}$, clusters were observed under single-collision conditions.

Theoretical studies by Castro and coworkers, utilising density functional theory methods, investigated the catalytic $\mathrm{N}_{2} \mathrm{O}$ reduction by $\mathrm{Rh}_{6}{ }^{-}$and $\mathrm{Rh}_{6}{ }^{+}$clusters ${ }^{46}$ as well as the lowsymmetry $\mathrm{Pt}_{8}$ cluster. ${ }^{47}$ We have previously reported IR-MPD studies of $\mathrm{N}_{2} \mathrm{O}$ binding on $\mathrm{Rh}_{n}{ }^{+}(n=4-8)^{48-50}$ and $\mathrm{Pt}_{n}{ }^{+}$clusters $(n=1-8) \cdot{ }^{51}$ Extensive IR-induced reactivity was observed in both cases, with excitation of infrared modes resulting in $\mathrm{N}_{2} \mathrm{O}$ decomposition. By way of comparison with these studies, we report here an IR-MPD study of $\mathrm{N}_{2} \mathrm{O}$ adsorption on isolated $\mathrm{Au}_{n}{ }^{+}(n \leq 7)$ and $\mathrm{Co}_{n}{ }^{+}(n \leq 5)$ clusters in which we investigate the nature of the molecular binding and its dependence on cluster size, electronic and geometrical structure.

\section{Experimental and computational methodology}

The instrument at the Fritz-Haber Institute along with the infrared multiple photon dissociation (IR-MPD) technique employed have been described previously and only brief details are given here. ${ }^{52,53}$ Gas-phase $\mathrm{M}_{n}\left(\mathrm{~N}_{2} \mathrm{O}\right)^{+}(\mathrm{M}=\mathrm{Co}, \mathrm{Au})$ clusters are formed by entraining metal atoms/ions produced by pulsed laser ablation of a rotating metal rod within an intense pulse of helium carrier gas (10 bar backing pressure), with nitrous oxide introduced downstream via a late mixing valve. Efficient clustering and thermalisation occurs via collisions within an aggregation channel before expansion into vacuum creating the molecular beam. The beam is skimmed for collimation and positively-charged clusters are detected by orthogonal extraction into a reflectron time-of-flight mass spectrometer. ${ }^{54}$ Experimental parameters such as the total backing pressure behind the pulsed valve, ablation laser power and nitrous oxide partial pressure are optimised for the generation of $\mathrm{M}_{n}\left(\mathrm{~N}_{2} \mathrm{O}\right)^{+}$ $(\mathrm{M}=\mathrm{Co}, \mathrm{Au} ; n \leq 8)$ species of interest. For these experiments the source was operated at room temperature and the cluster distribution is assumed to be in thermal equilibrium with this.

Intense tunable pulsed infrared radiation is provided by the free electron laser (FEL) at the Fritz-Haber Institute (FHI), ${ }^{53}$ operating in the regions of $1000-1400 \mathrm{~cm}^{-1}$ and $2100-2450 \mathrm{~cm}^{-1}$ and covering the $\nu_{1}(\mathrm{~N}=\mathrm{O})$ and $\nu_{3}(\mathrm{~N}=\mathrm{N})$ stretching modes of $\mathrm{N}_{2} \mathrm{O}$, respectively. ${ }^{55}$ The IR beam is collinear with and counterpropagates the molecular beam, and IR-MPD spectra are recorded by monitoring the loss of $\mathrm{N}_{2} \mathrm{O}$ from the parent $\mathrm{M}_{n}\left(\mathrm{~N}_{2} \mathrm{O}\right)^{+}$cluster as a function of wavenumber. ${ }^{56-62}$ In this way, photofragmentation provides a signature of IR absorption. To account for photon flux fluctuations, all experimental spectra were corrected for laser power.

To interpret the experimental vibrational spectra, quantum chemical calculations were performed, yielding structures and simulated infrared spectra of energetically low-lying isomers. Density functional theory (DFT) calculations were performed using the hybrid meta-GGA functional TPSSh, which includes $10 \%$ exact Hartree-Fock exchange, ${ }^{63}$ together with the Def2TZVP basis set, a combination which has worked well in previous studies. ${ }^{64,65}$ Relativistic effects, essential in describing gold chemistry, ${ }^{66-68}$ were incorporated by means of the ECP-60 effective core potential (ECP) ${ }^{69}$ for all but the 19 valence electrons of each gold atom. Def2-TZVP was also shown to accurately predict the IR spectra of $\mathrm{Rh}_{n}(\mathrm{CO})_{m}{ }^{+}$clusters. $^{70}$ The quadratically convergent SCF procedure was used along with $1.00 \times 10^{-6}$ hartree convergence criterion along with the Gaussian 09 "very tight" geometry optimisation convergence. ${ }^{71}$ Plausible $\mathrm{N}_{2} \mathrm{O}$ binding at atop, bridge, and three-body binding sites were investigated with $\mathrm{N}_{2} \mathrm{O}$ found to bind exclusively atop, favouring low coordinated gold/cobalt atoms, with $\mu_{2}$ and $\mu_{3}$ arrangements converging to atop structures upon geometry optimisation. The lowest energy structures found typically involve dissociatively-adsorbed nitrous oxide, with molecularly-bound structures representing entrance-channel complexes trapped behind an activation barrier. There is no evidence for dissociative structures in the experimental spectra; $\mathrm{N}_{2}$ almost certainly desorbs as a result of the exoergicity of the dissociation and subsequent O-atom binding. To better compare with experimental spectra, all simulated IR spectra reported here have been scaled by a factor 0.955 , determined from the simulated vibrational wavenumbers of isolated $\mathrm{N}_{2} \mathrm{O} .{ }^{55}$ All calculations were performed using the Gaussian09 suite of programs, ${ }^{71}$ and relative energies of structural isomers are given in electron 

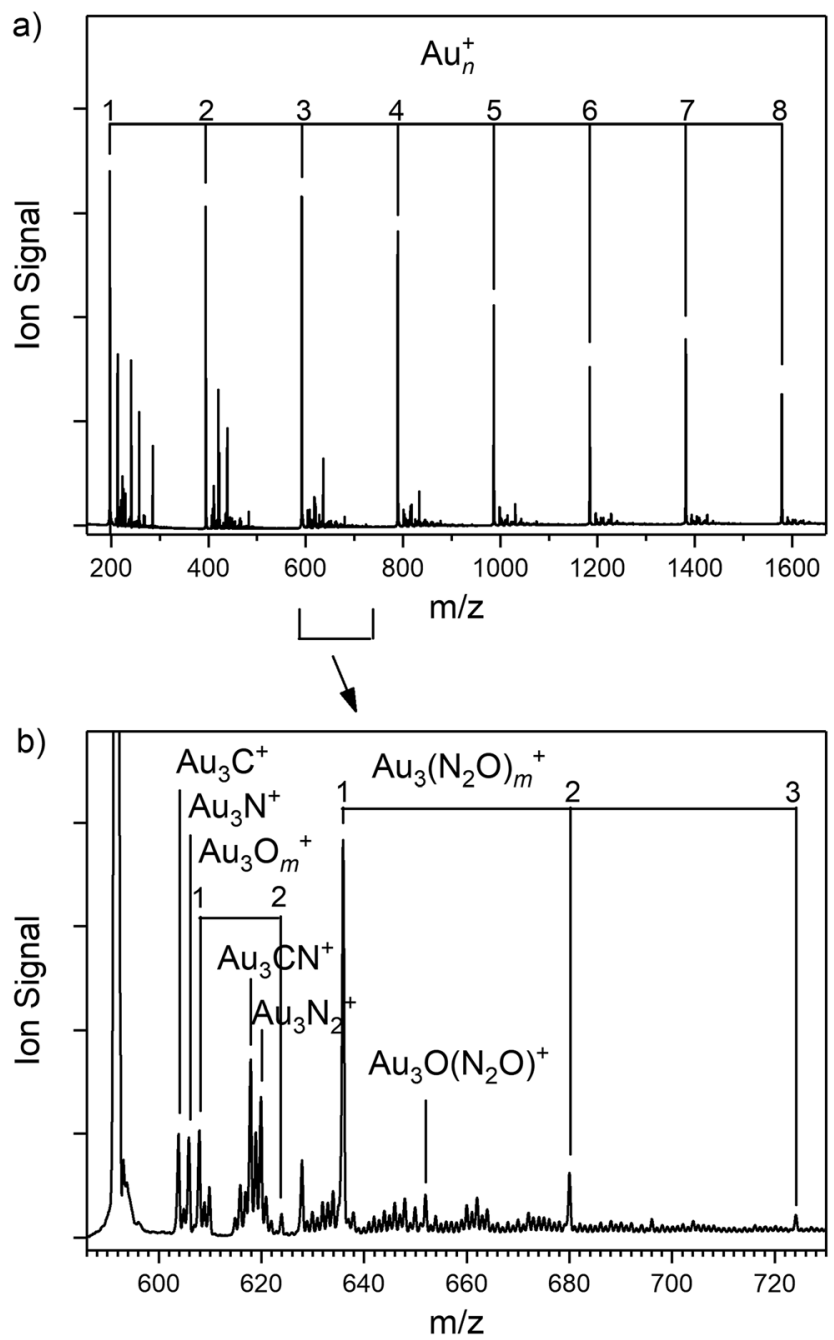

Fig. 1 (a and b) Time-of-flight mass spectrum of $\mathrm{Au}_{n}{ }^{+}$clusters produced by laser ablation of a gold rod in the presence of a helium carrier gas (10 bar backing pressure) and $\mathrm{N}_{2} \mathrm{O}$ added downstream in the cluster channel.

volts (eV), inclusive of zero-point energy. To accurately determine the multiplicity of each cluster structure, together with the relative energy, for each calculated structure the DFT wavefunction was stabilised and tested.

\section{Results and discussion}

\section{$3.1 \quad \mathrm{Au}_{n}\left(\mathrm{~N}_{2} \mathrm{O}\right)^{+}$clusters}

Fig. 1 presents the ToF mass spectrum showing the production of $\mathrm{Au}_{n}^{+}(n=1-8)$ clusters along with attached adsorbates. Besides the naked $\mathrm{Au}_{n}{ }^{+}$cluster cations, the most intense signals in the spectrum are the target $\mathrm{Au}_{n}\left(\mathrm{~N}_{2} \mathrm{O}\right)^{+}$clusters as well as additional peaks attributable to the simple cluster oxides, $\mathrm{Au}_{n} \mathrm{O}_{m}{ }^{+}$and, uniquely in the case of $n=1, \operatorname{AuO}\left(\mathrm{N}_{2} \mathrm{O}\right)^{+}$. Other species are observed, which we believe arise from reactions with trace hydrocarbons in the source, possibly introduced by glue used for sticking the rod to the holder. For the smallest, $n=1$ and 2 clusters, the species produced here are different to those observed by Dietrich et al. in their single-collision

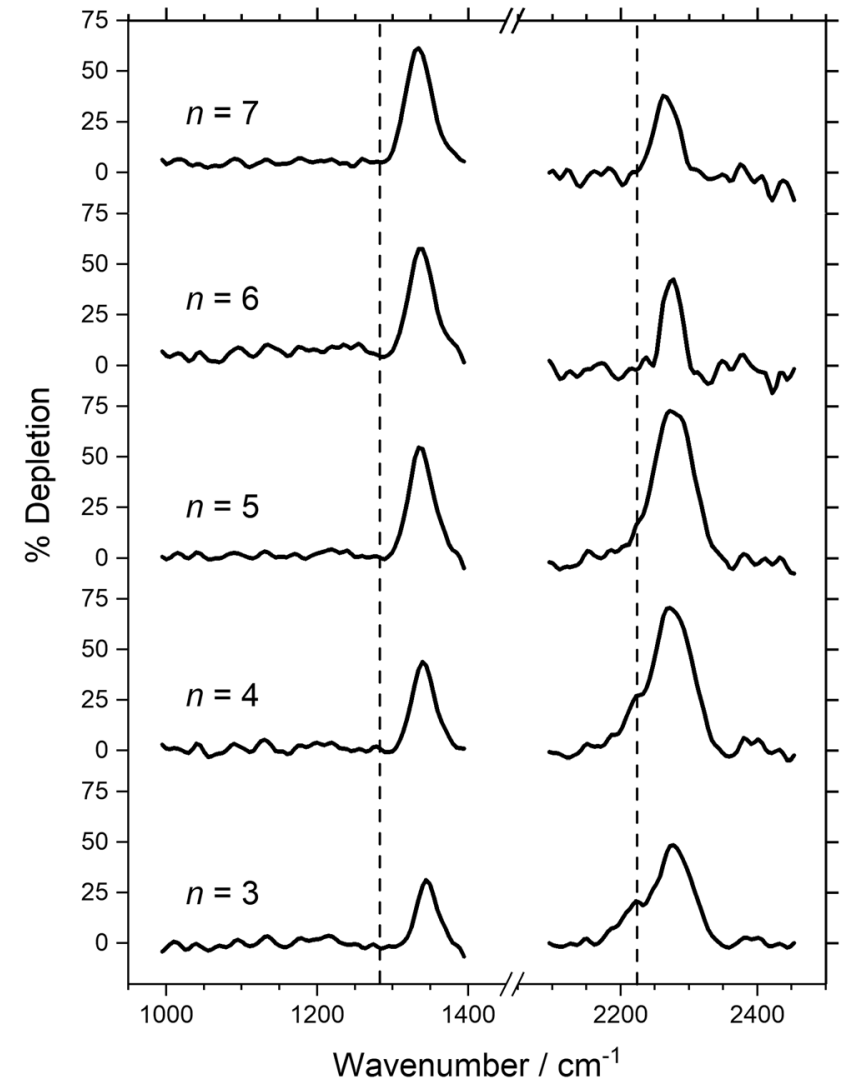

Fig. 2 IR-MPD depletion spectra of $\mathrm{Au}_{n}\left(\mathrm{~N}_{2} \mathrm{O}\right)^{+}(n=3-7)$ clusters with depletion given as a percentage of ion signal. The vertical dashed lines at 1285 and $2224 \mathrm{~cm}^{-1}$ indicate the wavenumber of the $\nu_{1}(\mathrm{~N}=\mathrm{O})$ and $\nu_{3}(\mathrm{~N}=\mathrm{N})$ modes in isolated $\mathrm{N}_{2} \mathrm{O}$, respectively. ${ }^{55}$

reaction study, reflecting the stabilising effect of collisions in the source employed here and the possible effects of fragmentation of larger clusters.

Fig. 2 shows an overview of the IR-MPD spectra for $\mathrm{Au}_{n}\left(\mathrm{~N}_{2} \mathrm{O}\right)^{+}(n=3-7)$ species recorded in the spectral region of both the $\mathrm{N}=\mathrm{O}\left(1000-1400 \mathrm{~cm}^{-1}\right)$ and $\mathrm{N}=\mathrm{N}\left(2100-2450 \mathrm{~cm}^{-1}\right)$ stretches and presented as depletion in the parent ion signal. The presence of intense depletion bands (in some cases exceeding $60 \%$ of the parent ion signal) close to the vibrational bands in free nitrous oxide confirms the molecular nature of the $\mathrm{N}_{2} \mathrm{O}$ binding. In this respect, $\mathrm{Au}_{n}\left(\mathrm{~N}_{2} \mathrm{O}\right)^{+}$clusters are similar to the isoelectronic $\mathrm{Au}_{n}(\mathrm{OCS})^{+}$species whose spectra we have reported recently. ${ }^{72}$ The spectra of the $n=1$ and 2 species unfortunately suffer from substantial distortions arising from dissociation of larger species (see Fig. S4 and S5, ESI $\dagger$ ).

In Fig. 2, a single band is observed in the $\mathrm{N}=\mathrm{O}$ stretch region around $1340 \mathrm{~cm}^{-1}$, blue-shifted up to $60 \mathrm{~cm}^{-1}$ from the $\nu_{1}$ mode of free $\mathrm{N}_{2} \mathrm{O}$ at $1285 \mathrm{~cm}^{-1} \cdot{ }^{55}$ The blue-shift reduces smoothly with increasing cluster size from $1345 \mathrm{~cm}^{-1}$ for $n=3$, to $1334 \mathrm{~cm}^{-1}$ for $n=7$. A similar trend is observed in the $\mathrm{N}=\mathrm{N}$ stretch region as the main band moves from $2278 \mathrm{~cm}^{-1}$ for $n=3$ to $2266 \mathrm{~cm}^{-1}$ for $n=7$, again slightly blue-shifted from the $\nu_{3}$ mode of $\mathrm{N}_{2} \mathrm{O}$ at $2224 \mathrm{~cm}^{-1}$. ${ }^{55}$ In the latter spectral region a weak shoulder to the main spectral feature is observed for 


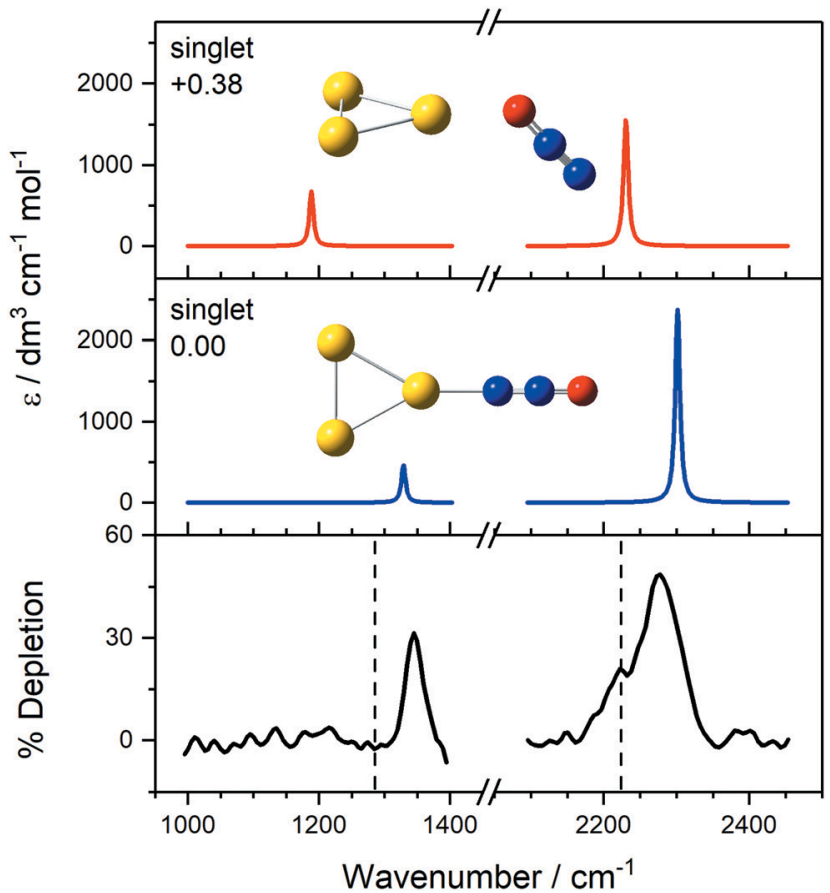

Fig. 3 IR-MPD spectrum of $\mathrm{Au}_{3}\left(\mathrm{~N}_{2} \mathrm{O}\right)^{+}$, along with simulated IR spectra of energetically low-lying isomers. The only low-lying electronic state is a singlet state and simulated IR bands corresponding to $\mathrm{N}$-bound and $\mathrm{O}$-bound isomers are indicated in blue and red, respectively. Energies are given in eV relative to the lowest molecularly bound isomer. The vertical dashed lines at 1285 and $2224 \mathrm{~cm}^{-1}$ indicate the wavenumber of the $\nu_{1}(\mathrm{~N}=\mathrm{O})$ and $\nu_{3}(\mathrm{~N}=\mathrm{N})$ modes in isolated $\mathrm{N}_{2} \mathrm{O}$, respectively. ${ }^{55}$

clusters $n=3$ and 4 , close to the free $\mathrm{N}_{2} \mathrm{O}$ stretch which is not present for the larger species.

Interpretation of the IR-MPD spectra is greatly assisted by simulated infrared spectra of energetically low-lying isomers identified using DFT. By way of example, the observed spectra of $\mathrm{Au}_{3}\left(\mathrm{~N}_{2} \mathrm{O}\right)^{+}$and $\mathrm{Au}_{4}\left(\mathrm{~N}_{2} \mathrm{O}\right)^{+}$are presented in Fig. 3 and 4, respectively, along with simulated spectra of low-lying structural isomers.

For $\mathrm{Au}_{3}\left(\mathrm{~N}_{2} \mathrm{O}\right)^{+}$(Fig. 3), the observed spectrum agrees very well with the simulated spectrum of the N-bound, lowest energy molecularly-bound structure with both spectral features blueshifted from the free $\mathrm{N}_{2} \mathrm{O}$ bands. With fractional depletion of $>50 \%$ observed, it is clear that this structure dominates the distribution. It is tempting to interpret the shoulder at $2223 \mathrm{~cm}^{-1}$ as the higher energy O-bound isomer but there is little evidence for the equivalent red-shifted band in the $\mathrm{N}=\mathrm{O}$ stretch region. By contrast, both $\mathrm{N}$ - and O-bound isomers were observed in our recent study of $\mathrm{Au}\left(\mathrm{N}_{2} \mathrm{O}\right)_{x}{ }^{+} \cdot{ }^{73}$ The origin of this shoulder remains unclear but could represent the presence of another N-bound isomer. Alternatively, it could result from spectral power broadening due to the increased FEL power in the $\mathrm{N}=\mathrm{N}$ stretching region and the fact that fewer higher energy photons are required for IR-MPD in this region.

In the case of $\mathrm{Au}_{4}\left(\mathrm{~N}_{2} \mathrm{O}\right)^{+}$(Fig. 4), a richer distribution of lowlying structural isomers is predicted. However, it is clear that the vibrational spectrum in this region is diagnostic only of the nitrous oxide binding motif and not of the metal cluster

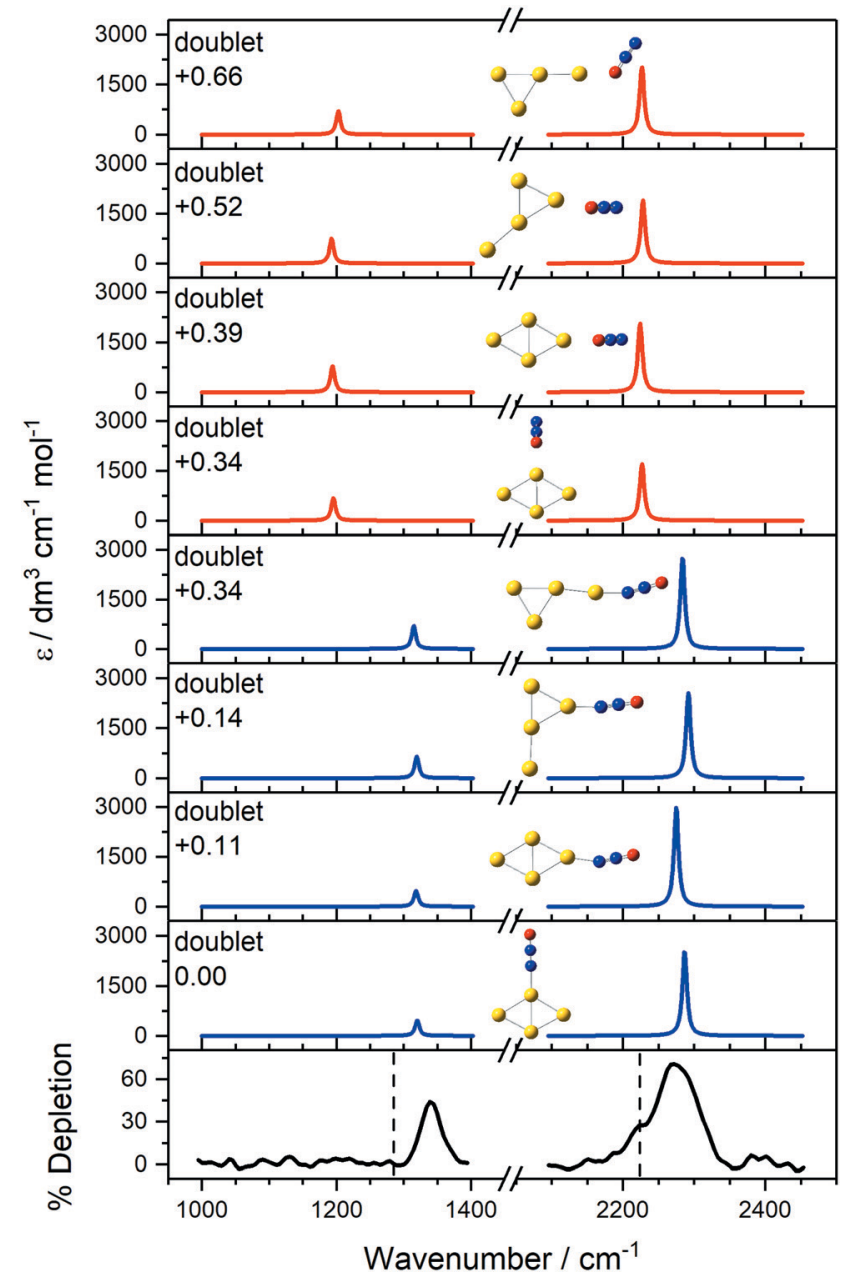

Fig. 4 IR-MPD depletion spectrum of $\mathrm{Au}_{4}\left(\mathrm{~N}_{2} \mathrm{O}\right)^{+}$, along with simulated IR spectra of low-lying isomers in the region of the $\mathrm{N}_{2} \mathrm{O} N=\mathrm{O}$ and $\mathrm{N}=\mathrm{N}$ stretches. The low-lying structures have doublet multiplicity. Simulated IR bands corresponding to $\mathrm{N}$-bound and $\mathrm{O}$-bound isomers are indicated in blue and red, respectively, with relative energies given in $\mathrm{eV}$. The vertical dashed lines at 1285 and $2224 \mathrm{~cm}^{-1}$ indicate the wavenumber of the $\nu_{1}(\mathrm{~N}=\mathrm{O})$ and $\nu_{3}(\mathrm{~N}=\mathrm{N})$ modes in isolated $\mathrm{N}_{2} \mathrm{O}$, respectively. ${ }^{55}$

structure. Again, the spectrum is dominated by N-bound structures with limited evidence for O-binding.

In both spectral regions, the weak blue shift observed in the $\mathrm{N}$-bound isomers relative to the free $\mathrm{N}_{2} \mathrm{O}$ stretches can be explained by $\sigma$-donation from the $7 \sigma$ (HOMO-1) orbital in $\mathrm{N}_{2} \mathrm{O}$ to the metal cluster, which is antibonding with respect to the $\mathrm{N}=\mathrm{N}$ bond. By contrast, O-binding, if present, would be signified by negligible shifts in the $\mathrm{N}=\mathrm{N}$ stretch region but a marked red shift in the $\mathrm{N}=\mathrm{O}$ band, reflecting an increased effective reduced mass. The nature of $\mathrm{N}_{2} \mathrm{O}$ binding to metal centres has been discussed extensively previously. ${ }^{4,73-75}$

The above interpretation of $\mathrm{Au}_{n}\left(\mathrm{~N}_{2} \mathrm{O}\right)^{+}$binding is readily extended to the larger, $n=5-7$ clusters, in which single blue-shifted bands in both spectral regions are again assigned to N-bound isomers.

\section{2 $\mathrm{Co}_{n}\left(\mathrm{~N}_{2} \mathrm{O}\right)^{+}$clusters}

Fig. 5 shows the ToF mass spectrum of $\mathrm{Co}_{n}{ }^{+}$-based clusters generated, exhibiting the production of $\mathrm{Co}_{n}\left(\mathrm{~N}_{2} \mathrm{O}\right)^{+}$species as far 
a)

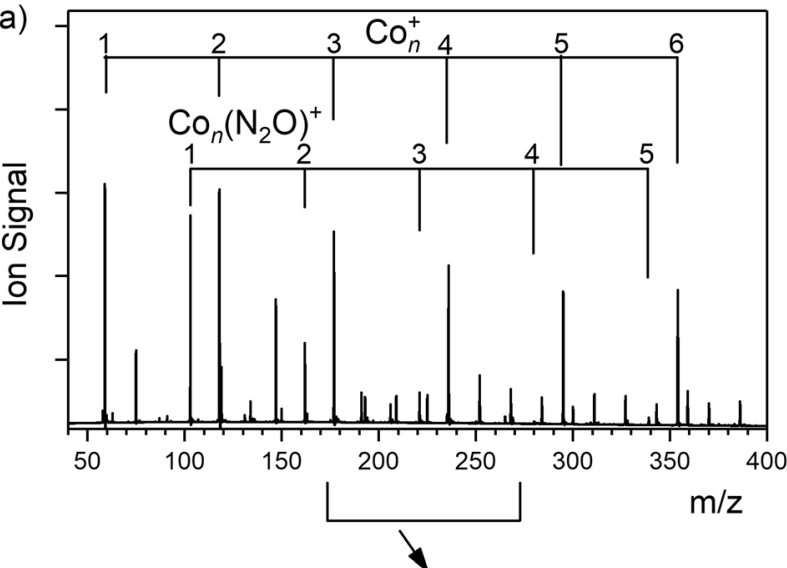

b)

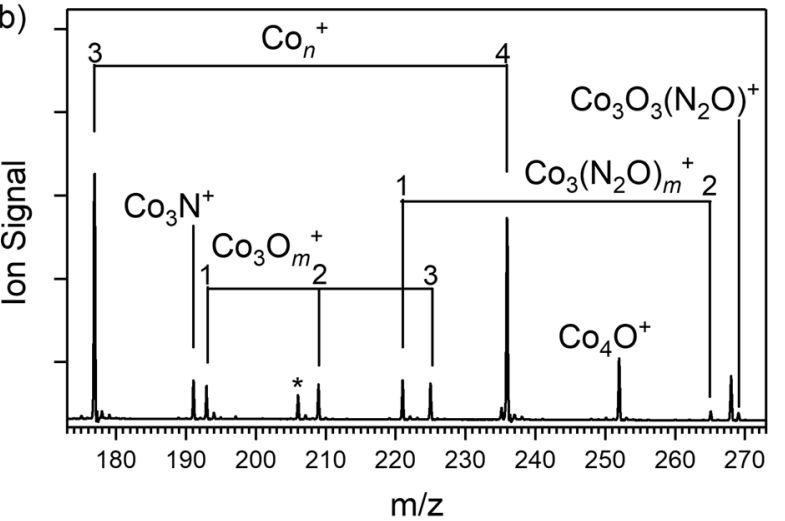

c)

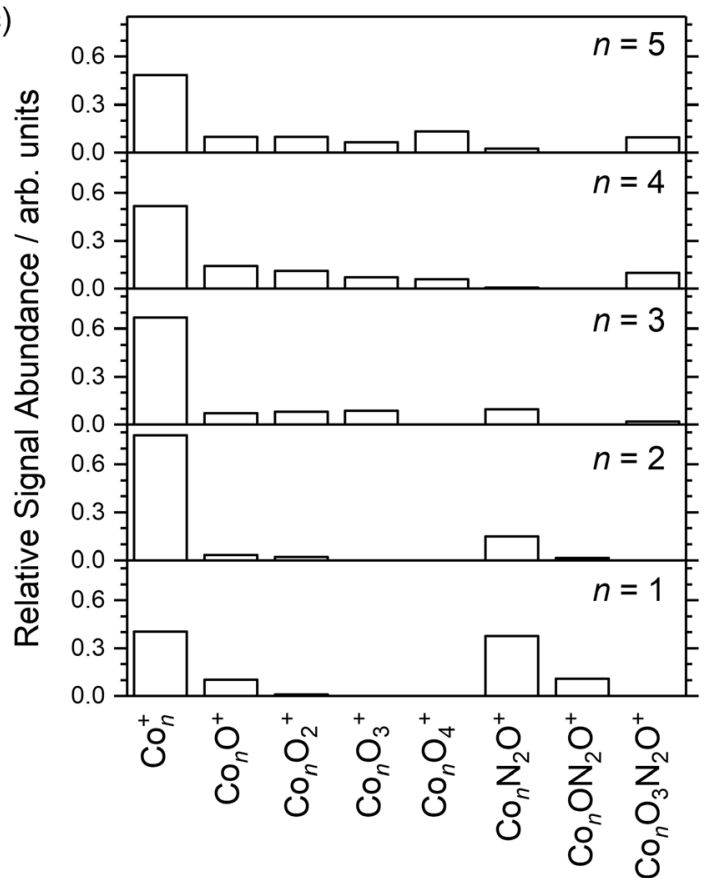

Fig. 5 ( $a$ and b) Mass spectrum of ions observed following ablation of a cobalt rod along with $\mathrm{N}_{2} \mathrm{O}$ added downstream in the cluster channel. For clarity, the mass signal for $\mathrm{CO}_{2}\left(\mathrm{~N}_{2} \mathrm{O}\right)_{2}{ }^{+}$is marked with an asterisk (*). (c) Histogram showing relative abundance of major species observed relative to the naked $\mathrm{Co}_{n}{ }^{+}$mass signal. The larger clusters react readily with $\mathrm{N}_{2} \mathrm{O}$ forming simple oxides.

as $n=5$. Considerably more $\mathrm{Co}_{n} \mathrm{O}_{m}{ }^{+}(m=1-4)$ oxidation products are observed than for the gold clusters (see Fig. $5 \mathrm{c}$ ).

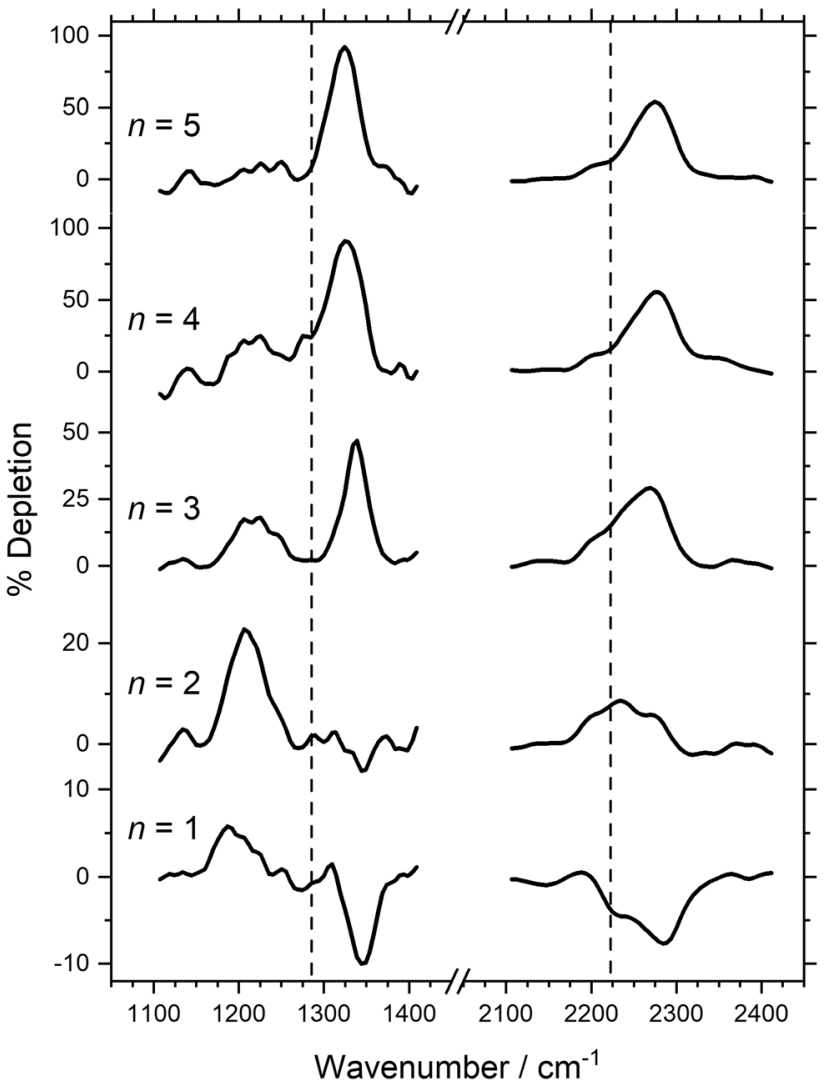

Fig. 6 IR-MPD depletion spectra of $\mathrm{Co}_{n}\left(\mathrm{~N}_{2} \mathrm{O}\right)^{+}(n=1-5)$ clusters in the $\mathrm{N}=\mathrm{O}$ and $\mathrm{N}=\mathrm{N}$ regions of $\mathrm{N}_{2} \mathrm{O}$. The vertical dashed lines at 1285 and $2224 \mathrm{~cm}^{-1}$ indicate the wavenumber of the $\nu_{1}(\mathrm{~N}=\mathrm{O})$ and $\nu_{3}(\mathrm{~N}=\mathrm{N})$ modes in isolated $\mathrm{N}_{2} \mathrm{O}$, respectively. ${ }^{55}$

However, care needs to be taken in ascribing these to reactions with particular $\mathrm{Co}_{n}{ }^{+}$clusters. Under single-collision conditions, the $\mathrm{Co}_{n}{ }^{+}+\mathrm{N}_{2} \mathrm{O}$ reaction has previously been shown to result in efficient fragmentation of metal clusters in this size regime, notably as $\mathrm{Co}_{n}{ }^{+}+\mathrm{N}_{2} \mathrm{O} \rightarrow \mathrm{Co}_{n-1} \mathrm{O}^{+}+\left[\mathrm{Co}, \mathrm{N}_{2}\right] \cdot{ }^{45}$ Hence, the observation of species such as $\mathrm{Co}_{5} \mathrm{O}_{4}{ }^{+}$almost certainly reflects reactions of larger clusters as well as $\mathrm{Co}_{5}{ }^{+}$itself.

Despite the abundance of oxides observed, sufficient $\mathrm{Co}_{n}\left(\mathrm{~N}_{2} \mathrm{O}\right)^{+}$signals were produced to permit IR-MPD spectra of $\mathrm{Co}_{n}\left(\mathrm{~N}_{2} \mathrm{O}\right)^{+}$clusters $(n=1-5)$ to be recorded, as shown in Fig. 6 . The spectra of the very smallest $(n=1,2)$ species again suffer enhancements (observed as negative depletions) due to fragmentation of larger and/or multiply decorated clusters, especially $\mathrm{Co}_{n}\left(\mathrm{~N}_{2} \mathrm{O}\right)_{2}{ }^{+}$, at the same wavenumber. Nevertheless, the observation of multiple spectral features in this region, including peaks red-shifted from the free $\mathrm{N}_{2} \mathrm{O}$ band, signifies the presence of both O-bound and $\mathrm{N}$-bound $\mathrm{N}_{2} \mathrm{O}$ cluster structures.

A mix of $\mathrm{N}$ - and O-bound isomers was observed in related IR spectra of $\mathrm{Co}\left(\mathrm{N}_{2} \mathrm{O}\right)_{x}^{+}$complexes in which the barrier for $\mathrm{N}_{2} \mathrm{O}$ free internal rotation in the $\mathrm{Co}\left(\mathrm{N}_{2} \mathrm{O}\right)^{+}$complex was calculated to be $c a .1 .3 \mathrm{eV}(0.8 \mathrm{eV}$ from the O-bound minimum) $){ }^{76}$ Given the rate of collisions in the cluster formation channel, it is thus likely that a fraction of complexes become trapped in low-lying excited isomeric forms behind barriers of this magnitude. 


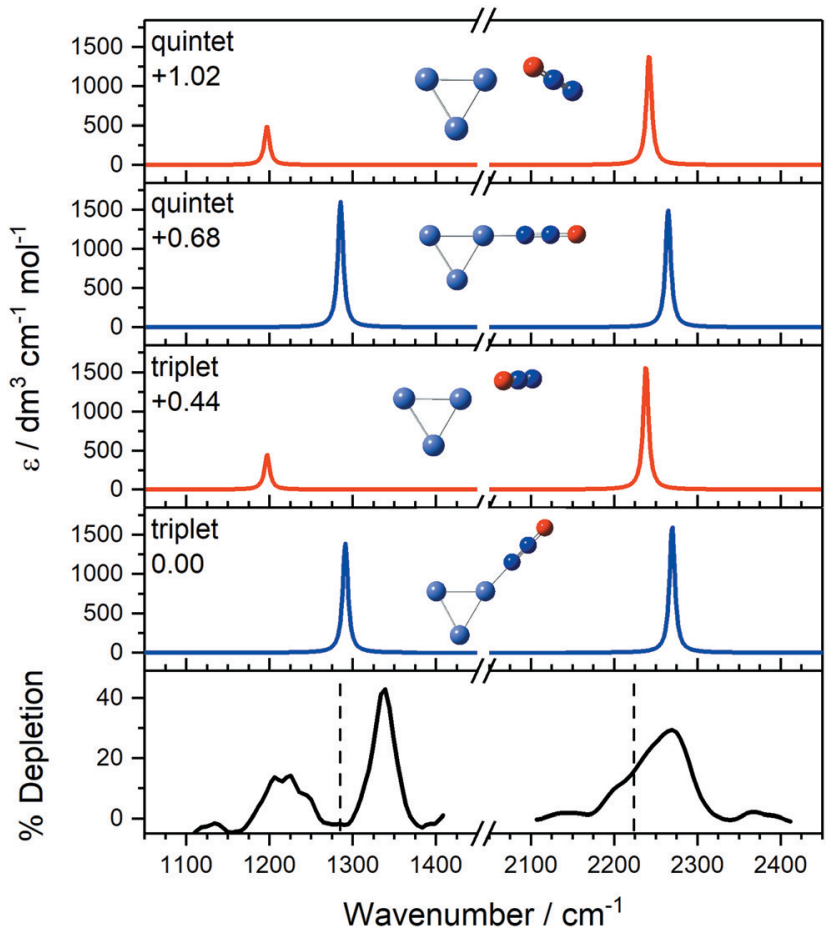

Fig. 7 IR-MPD depletion spectrum of $\mathrm{CO}_{3}\left(\mathrm{~N}_{2} \mathrm{O}\right)^{+}$, along with simulated IR spectra of low-lying isomers. Simulated IR spectra corresponding to $\mathrm{N}$-bound and $\mathrm{O}$-bound ligands are indicated in blue and red, respectively, for the two lowest energy calculated electronic states. The relative energies to the lowest molecularly bound isomer are given in eV. The vertical dashed lines at 1285 and $2224 \mathrm{~cm}^{-1}$ indicate the wavenumber of the $\nu_{1}(\mathrm{~N}=\mathrm{O})$ and $\nu_{3}(\mathrm{~N}=\mathrm{N})$ modes in isolated $\mathrm{N}_{2} \mathrm{O}$, respectively. ${ }^{55}$

The larger clusters, however, represent more effective thermal heat baths facilitating a more efficient annealing of structures. Hence, the spectra of the larger $n$ species are dominated by the lower energy N-bound isomers.

The strongest feature in the $\mathrm{N}=\mathrm{O}$ stretch region (ranging from $1345 \mathrm{~cm}^{-1}$ for $n=1$ to $1323 \mathrm{~cm}^{-1}$ for $n=5$ ) is characteristic of an N-bound structure. For $n=5$ this band exceeds $80 \%$ depletion suggesting this is the dominant structure present. The lower fractional depletions observed for smaller cluster sizes reflect the presence of other isomers in the beam. In the $\mathrm{N}=\mathrm{N}$ stretch region, by contrast, all spectra exhibit one main band slightly blue-shifted from the $\nu_{3}$ band of $\mathrm{N}_{2} \mathrm{O}$ with a shoulder observed very close to the free $\nu_{3}$ stretch. Similarly to the $\mathrm{N}=\mathrm{O}$ region, the main band is slightly more strongly blue-shifted for the smallest cluster, $n=1$, at $2280 \mathrm{~cm}^{-1}$ compared with $2271 \mathrm{~cm}^{-1}$ for $n=5$.

Fig. 7 compares the IR-MPD spectrum of $\mathrm{Co}_{3}\left(\mathrm{~N}_{2} \mathrm{O}\right)^{+}$together with simulated spectra for low-lying calculated triplet (lowest energy) and quintet (1st excited state) isomeric forms, confirming the assignments above. The strong bands at $1337 \mathrm{~cm}^{-1}$ and $2275 \mathrm{~cm}^{-1}$, each blue-shifted from the free $\mathrm{N}_{2} \mathrm{O}$ bands, are readily assigned as $\mathrm{N}$-bound structures (most likely the lowest-lying triplet state; IR-MPD is comparatively insensitive to cluster electronic state). The broad feature at $1219 \mathrm{~cm}^{-1}$ and the shoulder near $2220 \mathrm{~cm}^{-1}$, by contrast, agree well with simulated bands of the triplet O-bound isomer.
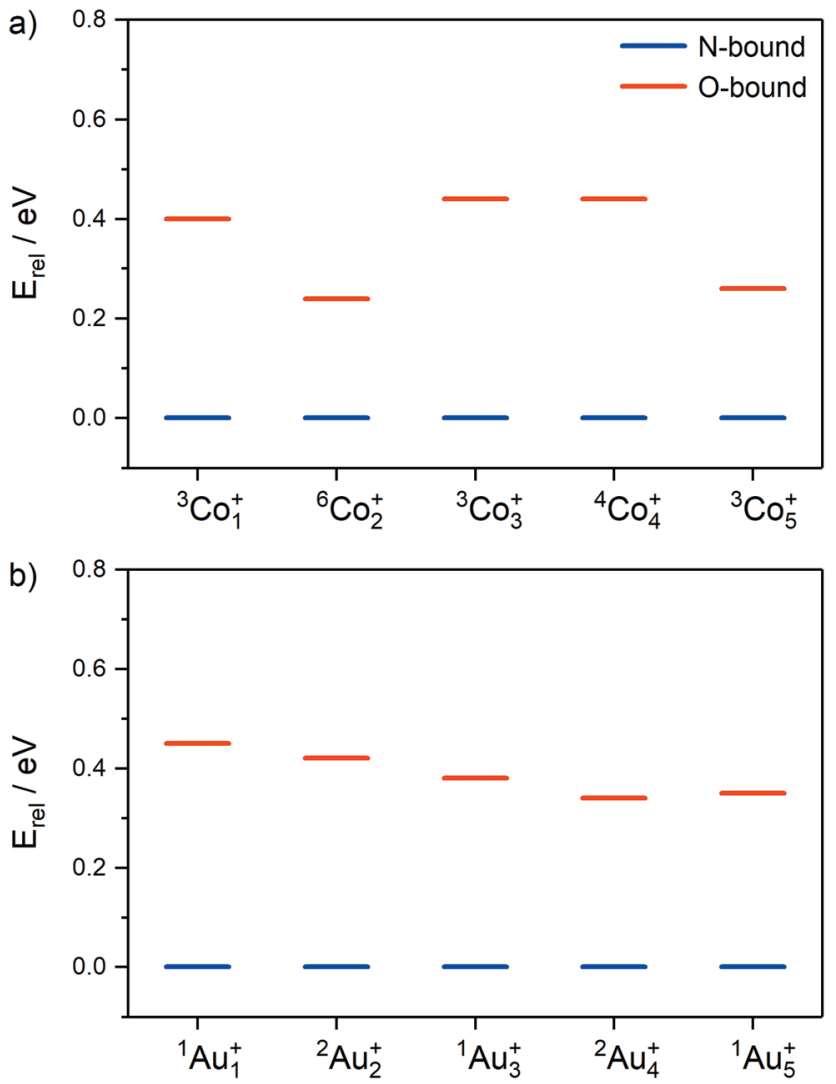

Fig. 8 Relative energies of lowest energy molecularly-bound $\mathrm{N}$ - (shown in blue) and O-bound isomers (red) for (a) $\mathrm{CO}_{n}\left(\mathrm{~N}_{2} \mathrm{O}\right)^{+}$and (b) $\mathrm{Au}_{n}\left(\mathrm{~N}_{2} \mathrm{O}\right)^{+}$ $(n=1-5)$

In addition to multiple isomers, $\mathrm{Co}_{n}\left(\mathrm{~N}_{2} \mathrm{O}\right)^{+}$clusters with $n=4$ and 5 are predicted to have several more low-lying electronic states, each with qualitatively similar IR spectra in this region (see ESI $\dagger$ ).

The relative energies of the lowest $\mathrm{N}$ - and $\mathrm{O}$-bound isomers of $\mathrm{M}_{n}\left(\mathrm{~N}_{2} \mathrm{O}\right)^{+}(\mathrm{M}=\mathrm{Co}, \mathrm{Au} ; n=1-5)$, are shown in Fig. 8 for the lowest energy electronic state in each case. For all cluster sizes, the N-bound isomers (blue) represent the lowest energy molecularly-bound structures, however the relative energies of the higher-lying O-bound structures (red) vary with cluster size, especially in the case of cobalt clusters.

In the case of $\mathrm{Au}_{n}\left(\mathrm{~N}_{2} \mathrm{O}\right)^{+}$, the energy difference between $\mathrm{N}$ - and O-bound isomers reduces smoothly with cluster size between $n=1(0.45 \mathrm{eV})$ and $n=5(0.35 \mathrm{eV})$. For the $\mathrm{Co}_{n}\left(\mathrm{~N}_{2} \mathrm{O}\right)^{+}$ clusters the picture is more complicated. Many more low-lying electronic states exist for the $\mathrm{Co}_{n}\left(\mathrm{~N}_{2} \mathrm{O}\right)^{+}$clusters (see $\mathrm{ESI} \dagger$ ), especially for the even $n$, odd electron clusters for which doublet, quartet and sextet states all lie within $1.3 \mathrm{eV}$ of the lowest energy structures. $\mathrm{Co}_{2}\left(\mathrm{~N}_{2} \mathrm{O}\right)^{+}$has an anomalously lowlying O-bound state (ca. $0.24 \mathrm{eV}$ in both doublet and sextet states). We have not calculated the barrier to internal $\mathrm{N}_{2} \mathrm{O}$ rotation for each cluster (which interchanges $\mathrm{N}$ - and O-bound isomers) but evidence of O-bound structures in the spectra of $\mathrm{Co}_{n}\left(\mathrm{~N}_{2} \mathrm{O}\right)^{+}$clusters suggests a significant barrier behind which the higher energy structures can be trapped. As discussed 

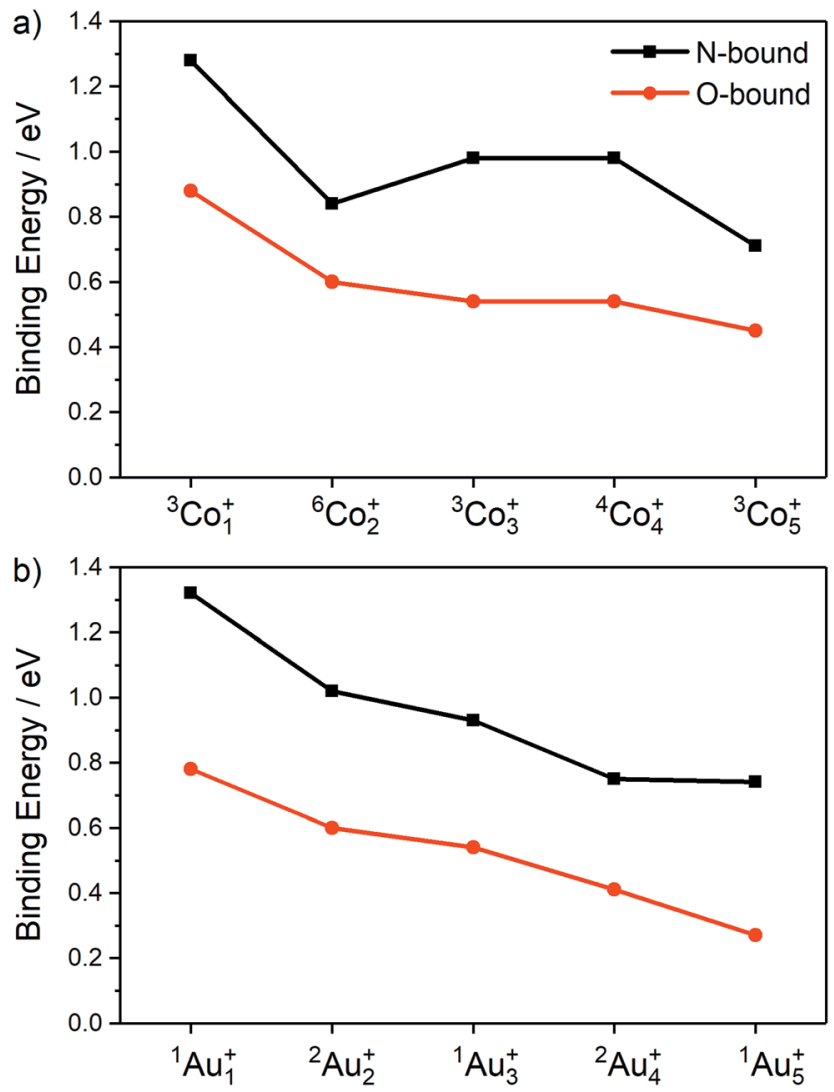

Fig. 9 Relative ligand binding energies (given as absolute values) of lowest energy molecularly-bound $\mathrm{N}$ - and $\mathrm{O}$-bound isomers for (a) $\mathrm{Co}_{n}\left(\mathrm{~N}_{2} \mathrm{O}\right)^{+}$ $(n=1-5)$, and (b) $\mathrm{Au}_{n}\left(\mathrm{~N}_{2} \mathrm{O}\right)^{+}(n=1-5)$, calculated as $E\left[\mathrm{M}_{n}\left(\mathrm{~N}_{2} \mathrm{O}\right)^{+}\right]-E\left[\mathrm{M}_{n}^{+}\right]-$ $E\left[\mathrm{~N}_{2} \mathrm{O}\right]$, including zero-point correction.

above, such structures have been observed in the spectra of $\mathrm{M}\left(\mathrm{N}_{2} \mathrm{O}\right)_{m}{ }^{+}$for several individual metal ions ${ }^{73,76,77}$ but IR-MPD studies of $\mathrm{Rh}_{n}\left(\mathrm{~N}_{2} \mathrm{O}\right)^{+}$and, recently, $\mathrm{Pt}_{n}\left(\mathrm{~N}_{2} \mathrm{O}\right)^{+}(n>2)$ clusters concluded that $\mathrm{N}_{2} \mathrm{O}$ binds exclusively via the terminal $\mathrm{N}$-atom. ${ }^{48,49,51}$ This suggests that, as well as larger metal clusters providing better annealing, the barriers to $\mathrm{N}_{2} \mathrm{O}$ rotation on $\mathrm{Co}_{n}{ }^{+}$are unusually large.

The calculated ligand binding energies of the lowest energy molecularly-bound $\mathrm{N}$ - and O-bound isomers for $\mathrm{Co}_{n}\left(\mathrm{~N}_{2} \mathrm{O}\right)^{+}$and $\mathrm{Au}_{n}\left(\mathrm{~N}_{2} \mathrm{O}\right)^{+}(n=1-5)$ are presented in Fig. 9 illustrating the higher binding energy of $\mathrm{N}$-bound structures relative to O-bound. The overall trend is for weaker binding with increased cluster size on both metals, though the N-bound isomer of $\mathrm{Co}_{2}\left(\mathrm{~N}_{2} \mathrm{O}\right)^{+}$is anomalously weakly bound.

\section{Conclusions}

The binding of nitrous oxide to small gas-phase $\mathrm{Au}_{n}{ }^{+}$and $\mathrm{Co}_{n}{ }^{+}$ clusters has been investigated using IR-MPD spectroscopy in conjunction with density functional theory calculations of energetically low-lying molecularly bound structures. In the case of $\mathrm{Au}_{n}\left(\mathrm{~N}_{2} \mathrm{O}\right)^{+}$, the lowest energy N-bound isomers dominate the observed spectra as indicated by the slight blue-shift of vibrational bands relative to free $\mathrm{N}_{2} \mathrm{O}$. For $\mathrm{Co}_{n}\left(\mathrm{~N}_{2} \mathrm{O}\right)^{+}$, a richer distribution of structural isomers is observed with clear evidence of both $\mathrm{N}$ - and $\mathrm{O}$-bound isomers in the distributions produced for the smaller clusters. Calculations suggest the presence of more low-lying electronic states in the case of $\mathrm{Co}_{n}{ }^{+}$but these are imperceptible in the vibrational spectra. In all cases investigated here, the only significant dissociation channel observed is the simple $\mathrm{N}_{2} \mathrm{O}$ ligand loss with little or no clear evidence for the type of photoinitiated intra-complex reactivity previously characterised in the case of analogous $\mathrm{Rh}_{n}\left(\mathrm{~N}_{2} \mathrm{O}\right)^{+}$and $\mathrm{Pt}_{n}\left(\mathrm{~N}_{2} \mathrm{O}\right)^{+}$clusters ${ }^{48-51}$ and, more widely, in $\mathrm{Au}_{n}(\mathrm{OCS})^{+}$and $\mathrm{Pt}_{n} \mathrm{O}_{m}(\mathrm{CO})^{+} \cdot{ }^{72,78}$ This suggests that the transition states for the $\mathrm{N}_{2} \mathrm{O}$ decomposition reaction on $\mathrm{Co}_{n}{ }^{+}$and $\mathrm{Au}_{n}{ }^{+}$lie significantly higher in energy than the $\mathrm{M}_{n}^{+}+\mathrm{N}_{2} \mathrm{O}$ dissociation asymptote.

\section{Statement of author contributions}

This work was conceived of by SRM, OD and AF and funded under their Oxford-Berlin Research Partnership grant designed to establish new collaborations between Oxford and Berlin. WS is responsible for the free electron laser at the Fritz-Haber Institute where all experiments were run. EMC, AEG, GM, PWB, and ASG visited Berlin for the experimental runs at which SS, KMP, KS and MF were also present. The computational studies were performed by EMC, AEG, GM and PWB. The manuscript was written in Oxford with contributions from all authors.

\section{Conflicts of interest}

There are no conflicts of interest to declare.

\section{Acknowledgements}

This work was funded partly by EPSRC under Programme Grants EP/L005913 and EP/T021675/1. EMC is also grateful to the EPSRC for his graduate studentship in Oxford. GM and AEG thank Worcester and Magdalen Colleges, Oxford, respectively for their graduate studentships. AF thanks the Deutsche Forschungsgemeinschaft for his Heisenberg Grant (FI 893/5). Financial support is also gratefully acknowledged from the Oxford-Berlin Research Partnership (Ref. OXBER_STEM5, "A Collaborative Approach to Understanding Nitrogen Oxide Reduction at Metal Centres"). The authors acknowledge the use of the University of Oxford Advanced Research Computing facility (https://doi.org/10.5281/zenodo.22558) and the HPC infrastructure LEO of the University of Innsbruck in carrying out the calculations presented in this work. Open Access funding provided by the Max Planck Society.

\section{References}

1 M. J. Prather, Time Scales in Atmospheric Chemistry: Coupled Perturbations to $\mathrm{N}_{2} \mathrm{O}, \mathrm{NO}_{\mathrm{y}}$, and $\mathrm{O}_{3}$, Science, 1998, 279, 1339-1341. 
2 A. R. Ravishankara, J. S. Daniel and R. W. Portmann, Nitrous Oxide $\left(\mathrm{N}_{2} \mathrm{O}\right)$ : The Dominant Ozone-Depleting Substance Emitted in the 21st Century, Science, 2009, 326, 123-125.

3 R. K. Pachauri, M. R. Allen, V. R. Barros, J. Broome, W. Cramer, R. Christ, J. A. Church, L. Clarke, Q. Dahe, P. Dasgupta, N. K. Dubash, O. Edenhofer, I. Elgizouli, C. B. Field, P. Forster, P. Friedlingstein, J. Fuglestvedt, L. Gomez-Echeverri, S. Hallegatte, G. Hegerl, M. Howden, K. Jiang, B. Jimenez Cisneroz, V. Kattsov, H. Lee, K. J. Mach, J. Marotzke, M. D. Mastrandrea, L. Meyer, J. Minx, Y. Mulugetta, K. O’Brien, M. Oppenheimer, J. J. Pereira, R. Pichs-Madruga, G.-K. Plattner, H.-O. Pörtner, S. B. Power, B. Preston, N. H. Ravindranath, A. Reisinger, K. Riahi, M. Rusticucci, R. Scholes, K. Seyboth, Y. Sokona, R. Stavins, T. F. Stocker, P. Tschakert, D. van Vuuren and J.-P. van Ypserle, Climate Change 2014: Synthesis Report. Contribution of Working Groups I, II and III to the Fifth Assessment Report of the Intergovernmental Panel on Climate Change, IPCC, Geneva, Switzerland, 2014.

4 W. B. Tolman, Binding and Activation of $\mathrm{N}_{2} \mathrm{O}$ at TransitionMetal Centers: Recent Mechanistic Insights, Angew. Chem., Int. Ed., 2010, 49, 1018-1024.

5 P. Chen, S. I. Gorelsky, S. Ghosh and E. I. Solomon, $\mathrm{N}_{2} \mathrm{O}$ Reduction by the $\mu 4$-Sulfide-Bridged Tetranuclear $\mathrm{CuZ}$ Cluster Active Site, Angew. Chem., Int. Ed., 2004, 43, 4132-4140.

6 V. Rosca, M. Duca, M. T. de Groot and M. T. M. Koper, Nitrogen Cycle Electrocatalysis, Chem. Rev., 2009, 109, 2209-2244.

7 E. L. Muetterties, T. N. Rhodin, E. Band, C. F. Brucker and W. R. Pretzer, Clusters and surfaces, Chem. Rev., 1979, 79, 91-137.

8 Z. Luo, A. W. Castleman and S. N. Khanna, Reactivity of Metal Clusters, Chem. Rev., 2016, 116, 14456-14492.

9 A. W. Castleman and K. H. Bowen, Clusters: Structure, Energetics, and Dynamics of Intermediate States of Matter, J. Phys. Chem., 1996, 100, 12911-12944.

10 A. W. Castleman and S. N. Khanna, Clusters, Superatoms, and Building Blocks of New Materials, J. Phys. Chem. C, 2009, 113, 2664-2675.

11 Z. Luo and A. W. Castleman, Special and General Superatoms, Acc. Chem. Res., 2014, 47, 2931-2940.

12 A. Sanchez, S. Abbet, U. Heiz, W.-D. Schneider, H. Häkkinen, R. N. Barnett and U. Landman, When Gold Is Not Noble: Nanoscale Gold Catalysts, J. Phys. Chem. A, 1999, 103, 9573-9578.

13 S. M. Lang, T. M. Bernhardt, R. N. Barnett, B. Yoon and U. Landman, Hydrogen-Promoted Oxygen Activation by Free Gold Cluster Cations, J. Am. Chem. Soc., 2009, 131, 8939-8951.

14 U. Landman, B. Yoon, C. Zhang, U. Heiz and M. Arenz, Factors in gold nanocatalysis: oxidation of $\mathrm{CO}$ in the nonscalable size regime, Top. Catal., 2007, 44, 145-158.

15 B. Yoon, H. Häkkinen, U. Landman, A. S. Wörz, J.-M. Antonietti, S. Abbet, K. Judai and U. Heiz, Charging Effects on Bonding and Catalyzed Oxidation of $\mathrm{CO}$ on $\mathrm{Au}_{8}$ Clusters on MgO, Science, 2005, 307, 403-407.
16 U. Landman, Materials by numbers: Computations as tools of discovery, Proc. Natl. Acad. Sci. U. S. A., 2005, 102, 6671-6678.

17 H. Häkkinen, S. Abbet, A. Sanchez, U. Heiz and U. Landman, Structural, Electronic, and Impurity-Doping Effects in Nanoscale Chemistry: Supported Gold Nanoclusters, Angew. Chem., Int. Ed., 2003, 42, 1297-1300.

18 M. Haruta, Size- and support-dependency in the catalysis of gold, Catal. Today, 1997, 36, 153-166.

19 M. Valden, X. Lai and D. W. Goodman, Onset of Catalytic Activity of Gold Clusters on Titania with the Appearance of Nonmetallic Properties, Science, 1998, 281, 1647-1650.

20 G. C. Bond and D. T. Thompson, Catalysis by Gold, Catal. Rev., 1999, 41, 319-388.

21 L. D. Socaciu, J. Hagen, T. M. Bernhardt, L. Wöste, U. Heiz, H. Häkkinen and U. Landman, Catalytic CO Oxidation by Free $\mathrm{Au}_{2}{ }^{-}$: Experiment and Theory, J. Am. Chem. Soc., 2003, 125, 10437-10445.

22 D. Schooss, P. Weis, O. Hampe and M. M. Kappes, Determining the size-dependent structure of ligand-free goldcluster ions, Philos. Trans. R. Soc., A, 2010, 368, 1211-1243.

23 A. P. Woodham and A. Fielicke, Gold Clusters, Colloids and Nano-Particles I, Springer International Publishing, 2014.

24 A. Zavras, G. N. Khairallah and R. A. J. O'Hair, Gold Clusters, Colloids and Nano-Particles II, Springer International Publishing, 2014.

25 P. R. Kemper and M. T. Bowers, Electronic-state chromatography: application to first-row transition-metal ions, J. Phys. Chem., 1991, 95, 5134-5146.

26 S. Gilb, P. Weis, F. Furche, R. Ahlrichs and M. M. Kappes, Structures of small gold cluster cations $\left(\mathrm{Au}_{\mathrm{n}}{ }^{+}, \mathrm{n}<14\right)$ : ion mobility measurements versus density functional calculations, J. Chem. Phys., 2002, 116, 4094-4101.

27 F. Furche, R. Ahlrichs, P. Weis, C. Jacob, S. Gilb, T. Bierweiler and M. M. Kappes, The structures of small gold cluster anions as determined by a combination of ion mobility measurements and density functional calculations, J. Chem. Phys., 2002, 117, 6982-6990.

28 A. Lechtken, D. Schooss, J. R. Stairs, M. N. Blom, F. Furche, N. Morgner, O. Kostko, B. von Issendorff and M. M. Kappes, $\mathrm{Au}_{34}{ }^{-}$: A Chiral Gold Cluster?, Angew. Chem., Int. Ed., 2007, 46, 2944-2948.

29 X. Xing, B. Yoon, U. Landman and J. H. Parks, Structural evolution of Au nanoclusters: from planar to cage to tubular motifs, Phys. Rev. B: Condens. Matter Mater. Phys., 2006, 74, 165423.

30 A. Shayeghi, R. Schäfer, D. M. Rayner, R. L. Johnston and A. Fielicke, Charge-induced dipole vs. relativistically enhanced covalent interactions in Ar-tagged Au-Ag tetramers and pentamers, J. Chem. Phys., 2015, 143, 024310.

31 A. Shayeghi, R. L. Johnston, D. M. Rayner, R. Schäfer and A. Fielicke, The Nature of Bonding between Argon and Mixed Gold-Silver Trimers, Angew. Chem., Int. Ed., 2015, 54, 10675-10680.

32 A. N. Gloess, H. Schneider, J. M. Weber and M. M. Kappes, Electronically excited states and visible region photodissociation spectroscopy of $\mathrm{Au}_{m}{ }^{+} \cdot \mathrm{Ar}_{n}$ clusters ( $\left.m=7-9\right)$ : 
Molecular dimensionality transition?, J. Chem. Phys., 2008, 128, 114312.

33 M. Förstel, W. Schewe and O. Dopfer, Optical Spectroscopy of the $\mathrm{Au}_{4}{ }^{+}$Cluster: The Resolved Vibronic Structure Indicates an Unexpected Isomer, Angew. Chem., Int. Ed., 2019, 58, 3356-3360.

34 P. Ferrari, G.-L. Hou, O. V. Lushchikova, F. Calvo, J. M. Bakker and E. Janssens, The structures of cationic gold clusters probed by far-infrared spectroscopy, Phys. Chem. Chem. Phys., 2020, 22, 11572-11577.

35 L. M. Ghiringhelli, P. Gruene, J. T. Lyon, D. M. Rayner, G. Meijer, A. Fielicke and M. Scheffler, Not so loosely bound rare gas atoms: finite-temperature vibrational fingerprints of neutral gold-cluster complexes, New J. Phys., 2013, 15, 083003.

36 P. Gruene, B. Butschke, J. T. Lyon, D. M. Rayner and A. Fielicke, Far-IR Spectra of Small Neutral Gold Clusters in the Gas Phase, Z. Phys. Chem., 2014, 228, 337-350.

37 B. R. Goldsmith, J. Florian, J.-X. Liu, P. Gruene, J. T. Lyon, D. M. Rayner, A. Fielicke, M. Scheffler and L. M. Ghiringhelli, Two-to-three dimensional transition in neutral gold clusters: the crucial role of van der Waals interactions and temperature, Phys. Rev. Mater., 2019, 3, 016002.

38 P. Gruene, D. M. Rayner, B. Redlich, A. F. G. van der Meer, J. T. Lyon, G. Meijer and A. Fielicke, Structures of Neutral $\mathrm{Au}_{7}, \mathrm{Au}_{19}$, and $\mathrm{Au}_{20}$ Clusters in the Gas Phase, Science, 2008, 321, 674-676.

39 G. Dietrich, K. Lützenkirchen, S. Becker, H.-U. Hasse, H.-J. Kluge, M. Lindinger, L. Schweikhard, J. Ziegler and S. Kuznetsov, Au-induced decomposition of $\mathrm{N}_{2} \mathrm{O}$, Ber. Bunsen-Ges., 1994, 98, 1608-1612.

40 A. Fielicke, G. von Helden, G. Meijer, B. Simard and D. M. Rayner, Direct observation of size dependent activation of NO on gold clusters, Phys. Chem. Chem. Phys., 2005, 7, 3906-3909.

41 R. Gehrke, P. Gruene, A. Fielicke, G. Meijer and K. Reuter, Nature of Ar bonding to small $\mathrm{Co}_{\mathrm{n}}{ }^{+}$clusters and its effect on the structure determination by far-infrared absorption spectroscopy, J. Chem. Phys., 2009, 130, 034306.

42 M. Jia, J. van der Tol, Y. Li, V. Chernyy, J. M. Bakker, L. N. Pham, M. T. Nguyen and E. Janssens, Structures and magnetic properties of small $\mathrm{Co}^{+}{ }_{\mathrm{n}}$ and $\mathrm{Co}_{\mathrm{n}-1} \mathrm{Cr}^{+}(\mathrm{n}=3-5)$ clusters, J. Phys.: Condens. Matter, 2018, 30, 474002.

43 V. Zamudio-Bayer, K. Hirsch, A. Langenberg, A. Lawicki, A. Terasaki, B. von Issendorff and J. T. Lau, Large orbital magnetic moments of small, free cobalt cluster ions $\mathrm{Co}_{\mathrm{n}}{ }^{+}$ with $\mathrm{n} \leq$ 9, J. Phys.: Condens. Matter, 2018, 30, 464002.

44 J. M. Bakker, J. Jalink, D. Dieleman and A. Kirilyuk, Structural determination of neutral $\mathrm{Co}_{n}$ clusters $(\mathrm{n}=4-10,13)$ through IR-UV two-color vibrational spectroscopy and DFT calculations, J. Phys.: Condens. Matter, 2018, 30, 494003.

45 M. L. Anderson, A. Lacz, T. Drewello, P. J. Derrick, D. P. Woodruff and S. R. Mackenzie, The chemistry of nitrogen oxides on small size-selected cobalt clusters, $\mathrm{Co}_{\mathrm{n}}{ }^{+}$, J. Chem. Phys., 2009, 130, 064305.

46 H. Francisco, V. Bertin, J. R. Soto and M. Castro, Charge and Geometrical Effects on the Catalytic $\mathrm{N}_{2} \mathrm{O}$ Reduction by $\mathrm{Rh}_{6}{ }^{-}$ and $\mathrm{Rh}_{6}{ }^{+}$Clusters, J. Phys. Chem. C, 2016, 120, 23648-23659.
47 E. Hernández, V. Bertin, J. Soto, A. Miralrio and M. Castro, Catalytic Reduction of Nitrous Oxide by the Low-Symmetry $\mathrm{Pt}_{8}$ Cluster, J. Phys. Chem. A, 2018, 122, 2209-2220.

48 S. M. Hamilton, W. S. Hopkins, D. J. Harding, T. R. Walsh, P. Gruene, M. Haertelt, A. Fielicke, G. Meijer and S. R. Mackenzie, Infrared Induced Reactivity on the Surface of Isolated Size-Selected Clusters: Dissociation of $\mathrm{N}_{2} \mathrm{O}$ on Rhodium Clusters, J. Am. Chem. Soc., 2010, 132, 1448-1449.

49 S. M. Hamilton, W. S. Hopkins, D. J. Harding, T. R. Walsh, M. Haertelt, C. Kerpal, P. Gruene, G. Meijer, A. Fielicke and S. R. Mackenzie, Infrared-Induced Reactivity of $\mathrm{N}_{2} \mathrm{O}$ on Small Gas-Phase Rhodium Clusters, J. Phys. Chem. A, 2011, 115, 2489-2497.

50 A. C. Hermes, S. M. Hamilton, W. S. Hopkins, D. J. Harding, C. Kerpal, G. Meijer, A. Fielicke and S. R. Mackenzie, Effects of Coadsorbed Oxygen on the Infrared Driven Decomposition of $\mathrm{N}_{2} \mathrm{O}$ on Isolated $\mathrm{Rh}_{5}{ }^{+}$Clusters, J. Phys. Chem. Lett., 2011, 2, 3053-3057.

51 G. Meizyte, A. E. Green, A. S. Gentleman, S. Schaller, W. Schöllkopf, A. Fielicke and S. R. Mackenzie, Free electron laser infrared action spectroscopy of nitrous oxide binding to platinum clusters, $\mathrm{Pt}_{\mathrm{n}}\left(\mathrm{N}_{2} \mathrm{O}\right)_{\mathrm{m}}{ }^{+}$, Phys. Chem. Chem. Phys., 2020, 22, 18606-18613.

52 A. Fielicke, G. von Helden and G. Meijer, Far-Infrared spectroscopy of isolated transition metal clusters, Eur. Phys. J. $D, 2005,34,83-88$.

53 W. Schöllkopf, S. Gewinner, H. Junkes, A. Paarmann, G. von Helden, H. P. Bluem and A. M. M. Todd, Advances in X-ray Free-Electron Lasers Instrumentation III, International Society for Optics and Photonics, 2015, vol. 9512, p. 95121L.

54 B. A. Mamyrin, V. I. Karataev, D. V. Shmikk and V. A. Zagulin, The mass-reflectron, a new nonmagnetic time-offlight mass spectrometer with high resolution, J. Exp. Theor. Phys., 1973, 37, 45.

55 G. Herzberg, Molecular Spectra and Molecular Structure: II Infrared and Raman Spectra of Polyatomic Molecules, Krieger, Malabar, Florida, 1991, vol. 2.

56 O. Rodriguez and J. M. Lisy, Infrared Spectroscopy of $\mathrm{Li}^{+}\left(\mathrm{CH}_{4}\right)_{1} \mathrm{Ar}_{\mathrm{n}}, \mathrm{n}=1-6$, Clusters, J. Phys. Chem. A, 2011, 115, 1228-1233.

57 O. Rodriguez and J. M. Lisy, Infrared spectroscopy of $\mathrm{Li}^{+}\left(\mathrm{CH}_{4}\right)_{\mathrm{n}}, \mathrm{n}=1-9$, clusters, Chem. Phys. Lett., 2011, 502, 145-149.

58 P. Ayotte, G. H. Weddle, J. Kim and M. A. Johnson, Vibrational Spectroscopy of the Ionic Hydrogen Bond: Fermi Resonances and Ion-Molecule Stretching Frequencies in the Binary $\mathrm{X}^{-} \cdot \mathrm{H}_{2} \mathrm{O}(\mathrm{X}=\mathrm{Cl}, \mathrm{Br}, \mathrm{I})$ Complexes via Argon Predissociation Spectroscopy, J. Am. Chem. Soc., 1998, 120, 12361-12362.

59 M. Okumura, L. I. Yeh, J. D. Myers and Y. T. Lee, Infrared spectra of the solvated hydronium ion: vibrational predissociation spectroscopy of mass-selected $\mathrm{H}_{3} \mathrm{O}^{+} \cdot\left(\mathrm{H}_{2} \mathrm{O}\right)_{\mathrm{n}}\left(\mathrm{H}_{2}\right)_{\mathrm{m}}$, J. Phys. Chem., 1990, 94, 3416-3427.

60 M. Okumura, L. I. Yeh, J. D. Myers and Y. T. Lee, Infrared spectra of the cluster ions $\mathrm{H}_{7} \mathrm{O}_{3}{ }^{+} \cdot \mathrm{H}_{2}$ and $\mathrm{H}_{9} \mathrm{O}_{4}{ }^{+} \cdot \mathrm{H}_{2}, J$. Chem. Phys., 1986, 85, 2328-2329. 
61 M. B. Knickelbein and W. J. C. Menezes, Metal cluster-rare gas van der Waals complexes: physisorption on a microscopic scale, J. Phys. Chem., 1992, 96, 6611-6616.

62 W. Herschel, XIV. Experiments on the refrangibility of the invisible rays of the sun, Philos. Trans. R. Soc. London, 1800, 90, 284-292.

63 V. N. Staroverov, G. E. Scuseria, J. Tao and J. P. Perdew, Comparative assessment of a new nonempirical density functional: molecules and hydrogen-bonded complexes, J. Chem. Phys., 2003, 119, 12129-12137.

64 F. Weigend and R. Ahlrichs, Balanced basis sets of split valence, triple zeta valence and quadruple zeta valence quality for $\mathrm{H}$ to $\mathrm{Rn}$ : design and assessment of accuracy, Phys. Chem. Chem. Phys., 2005, 7, 3297-3305.

65 F. Weigend, Accurate Coulomb-fitting basis sets for $\mathrm{H}$ to $\mathrm{Rn}$, Phys. Chem. Chem. Phys., 2006, 8, 1057-1065.

66 P. Pyykkö, Theoretical Chemistry of Gold, Angew. Chem., Int. Ed., 2004, 43, 4412-4456.

67 P. Pyykkö, Theoretical chemistry of gold. II, Inorg. Chim. Acta, 2005, 358, 4113-4130.

68 P. Pyykkö, Theoretical chemistry of gold. III, Chem. Soc. Rev., 2008, 37, 1967-1997.

69 D. Andrae, U. Häußermann, M. Dolg, H. Stoll and H. Preuß, Energy-adjusted ab initio pseudopotentials for the second and third row transition elements, Theor. Chim. Acta, 1990, 77, 123-141.

70 I. Swart, F. M. F. de Groot, B. M. Weckhuysen, D. M. Rayner, G. Meijer and A. Fielicke, The Effect of Charge on CO Binding in Rhodium Carbonyls: From Bridging to Terminal CO, J. Am. Chem. Soc., 2008, 130, 2126-2127.

71 M. J. Frisch, G. W. Trucks, H. B. Schlegel, G. E. Scuseria, M. A. Robb, J. R. Cheeseman, G. Scalmani, V. Barone, B. Mennucci, G. A. Petersson, H. Nakatsuji, M. Caricato, X. Li, H. P. Hratchian, A. F. Izmaylov, J. Bloino, G. Zheng, J. L. Sonnenberg, M. Hada, M. Ehara, K. Toyota, R. Fukuda, J. Hasegawa, M. Ishida, T. Nakajima, Y. Honda, O. Kitao, H. Nakai, T. Vreven, J. A. Montgomery, J. E. Peralta, F. Ogliaro, M. Bearpark, J. J. Heyd, E. Brothers, K. N. Kudin, V. N. Staroverov, R. Kobayashi, J. Normand,
K. Raghavachari, A. Rendell, J. C. Burant, S. S. Iyengar, J. Tomasi, M. Cossi, N. Rega, J. M. Millam, M. Klene, J. E. Knox, J. B. Cross, V. Bakken, C. Adamo, J. Jaramillo, R. Gomperts, R. E. Stratmann, O. Yazyev, A. J. Austin, R. Cammi, C. Pomelli, J. W. Ochterski, R. L. Martin, K. Morokuma, G. Zakrzewski, G. A. Voth, P. Salvador, J. J. Dannenberg, S. Dapprich, A. D. Daniels, O. Farkas, J. B. Foresman, J. V. Ortiz, J. Cioslowski and D. J. Fox, Gaussian 09, Revision D.01, Gaussian, Inc., Wallingford CT, 2009.

72 A. E. Green, S. Schaller, G. Meizyte, B. J. Rhodes, S. P. Kealy, A. S. Gentleman, W. Schöllkopf, A. Fielicke and S. R. Mackenzie, Infrared Study of OCS Binding and SizeSelective Reactivity with Gold Clusters, $\mathrm{Au}_{\mathrm{n}}{ }^{+}(\mathrm{n}=1-10)$, J. Phys. Chem. A, 2020, 124, 5389-5401.

73 E. M. Cunningham, A. S. Gentleman, P. W. Beardsmore, A. Iskra and S. R. Mackenzie, Infrared Signature of Structural Isomers of Gas-Phase $\mathrm{M}^{+}\left(\mathrm{N}_{2} \mathrm{O}\right)_{\mathrm{n}}(\mathrm{M}=\mathrm{Cu}, \mathrm{Ag}$, Au) Ion-Molecule Complexes, J. Phys. Chem. A, 2017, 121, 7565-7571.

74 X. Jin, G. Wang and M. Zhou, Matrix Isolation Infrared Spectroscopic and Theoretical Study of Nickel, Palladium, and Platinum Nitrous Oxide Complexes, J. Phys. Chem. A, 2006, 110, 8017-8022.

75 G. Wang, X. Jin, M. Chen and M. Zhou, Matrix isolation infrared spectroscopic and theoretical study of the copper (I) and silver (I)-nitrous oxide complexes, Chem. Phys. Lett., 2006, 420, 130-134.

76 E. M. Cunningham, A. S. Gentleman, P. W. Beardsmore and S. R. Mackenzie, Structural isomers and low-lying electronic states of gas-phase $\mathrm{M}^{+}\left(\mathrm{N}_{2} \mathrm{O}\right)_{\mathrm{n}}(\mathrm{M}=\mathrm{Co}, \mathrm{Rh}, \mathrm{Ir})$ ion-molecule complexes, Phys. Chem. Chem. Phys., 2019, 21, 13959-13967.

77 E. M. Cunningham, A. S. Gentleman, P. W. Beardsmore and S. R. Mackenzie, Infrared spectroscopy of closed s-shell gasphase $\mathrm{M}^{+}\left(\mathrm{N}_{2} \mathrm{O}\right)_{\mathrm{n}}(\mathrm{M}=\mathrm{Li}, \mathrm{Al})$ ion-molecule complexes, Mol. Phys., 2019, 117, 2990-3000.

78 A. C. Hermes, S. M. Hamilton, G. A. Cooper, C. Kerpal, D. J. Harding, G. Meijer, A. Fielicke and S. R. Mackenzie, Infrared driven $\mathrm{CO}$ oxidation reactions on isolated platinum cluster oxides, $\mathrm{Pt}_{\mathrm{n}} \mathrm{O}_{\mathrm{m}}{ }^{+}$, Faraday Discuss., 2012, 157, 213-225. 